\title{
Treatment outcomes of extended-field radiation therapy and the effect of concurrent chemotherapy on uterine cervical cancer with para-aortic lymph node metastasis
}

Hong In Yoon ${ }^{1,5}$, Jihye Cha², Ki Chang Keum ${ }^{1,6}$, Ha Yoon Lee', Eun Ji Nam³ ${ }^{3}$ Sang Wun Kim³ ${ }^{3}$ Sunghoon Kim³, Young Tae Kim ${ }^{3}$, Gwi Eon $\mathrm{Kim}^{4}$ and Yong Bae Kim ${ }^{1,6^{*}}$

\begin{abstract}
Purpose: To review the clinical outcomes of extended-field radiation therapy (EFRT) and to analyze prognostic factors significant for survival in patients receiving EFRT for uterine cervical carcinoma with para-aortic node (PAN) metastasis.

Patients and methods: We retrospectively reviewed 90 patients with stage IB-IVA cervical cancer and PAN metastasis between 1987 and 2012. Median age was 50 (range, 24-77). Patients received median 70.2 Gy (range, 56-93) to point A and median 50.4 Gy (range, 45-60.4) to PAN over median 69 elapsed days (range, 43-182). Forty-six patients (51.1\%) received concurrent chemotherapy. Survival was calculated using the Kaplan-Meier method. We analyzed prognostic factors for overall actuarial survival (OS) and progression-free survival (PFS) using a Cox regression method.

Results: The median follow-up period for surviving patients was 55 months (range, 3-252). Seventy patients (77.8\%) had complete remission. Forty-six patients experienced treatment failure as follows: 11 patients (12.2\%) as local recurrence, 19 (21\%) as regional recurrence and 33 (36.7\%) as distant metastasis. The 5-yr OS and PFS were 62.6\% and 43.9\%, respectively. Treatment response was the only statistically independent prognostic factors for OS $(p=0.04)$ and PFS $(p<0.001)$ on multivariate analysis. Grade 3 or 4 hematologic gastrointestinal and urogenital toxicities were observed in about 10\% of patients.

Conclusions: Our institutional experiences showed that EFRT was an effective treatment for cervical cancer patients with PAN metastasis. The addition of chemotherapy to EFRT seems to have uncertain survival benefit with higher hematologic toxicity.
\end{abstract}

Keywords: Cervical cancer, Treatment outcome, Chemotherapy, Para-aortic lymph node, Extended-field radiation therapy

\section{Introduction}

Para-aortic node (PAN) metastasis is an important prognostic factor, although the International Federation of Gynecology and Obstetrics (FIGO) staging system of uterine cervical cancer does not allow for the involvement of nodes [1]. According to the Gynecologic Oncology Group, biopsy-confirmed PAN involvement was found in 5\% of Stage IB patients, $17 \%$ of Stage IIB patients, and $25 \%$ of

\footnotetext{
* Correspondence: ybkim3@yuhs.ac

'Department of Radiation Oncology, Yonsei Cancer Center, Yonsei University College of Medicine, 50-1 Yonsei-ro, Seodaemun-gu, Seoul 120-752, Korea

${ }^{6}$ Yonsei Song-Dang Institute for Cancer Research, Yonsei University College of Medicine, Seoul, Korea

Full list of author information is available at the end of the article
}

Stage IIIB patients; poor survival rates of these patients were reported [2].

Extended-field radiation therapy (EFRT) is conventionally indicated for cervical cancer patients with grossly detected common iliac or PAN metastasis. In several previous studies on EFRT, a 5-year overall survival rate of $29-32 \%$ was reported [3-5]. In some prospective and retrospective trials with EFRT plus concurrent chemotherapy, severe toxicity of EFRT plus concurrent chemotherapy, including gastrointestinal or hematologic toxicity, was observed despite a favorable survival rate [6-8]. Therefore, some investigators have tried to reduce the toxicity of EFRT plus concurrent chemotherapy using intensity-modulated radiotherapy or

\section{Ciomed Central}

(c) 2015 Yoon et al.; licensee BioMed Central. This is an Open Access article distributed under the terms of the Creative Commons Attribution License (http://creativecommons.org/licenses/by/4.0), which permits unrestricted use, distribution, and reproduction in any medium, provided the original work is properly credited. The Creative Commons Public Domain Dedication waiver (http://creativecommons.org/publicdomain/zero/1.0/) applies to the data made available in this article unless otherwise stated. 
low dose chemotherapy $[9,10]$. However, despite a large number of small population studies, the effect of EFRT with or without concurrent chemotherapy has still not been elucidated.

The purpose of this study was to investigate the clinical outcomes, including toxicity, treatment response, patterns of failure, and survival, as well as to analyze prognostic factors significant for survival, in patients receiving EFRT for uterine cervical carcinoma with PAN metastasis.

\section{Methods and materials}

\section{Patient selection and characteristics}

This retrospective study received approval from the internal review boards of the participating institution (IRB No. 42014-0162). Between April 1987 and December 2012, 123 patients with cervical cancer and PAN metastasis were treated with EFRT at our institution. Among them, 33 patients were excluded if any of the following conditions were met: (1) stage IVB, (2) distant nodal metastasis in inguinal, mediastinal or supraclavicular lymphatics, (3) salvage, palliative, or postoperative RT, (4) induction or post-RT chemotherapy, (5) incomplete RT due to patient refusal. Consequently, 90 patients were included in this retrospective study. Clinical staging was based on the FIGO stage classifications updated in 2009 [11]. The procedure for staging included a detailed history and a physical examination, common laboratory tests, standard chest radiographs, intravenous pyelograms, barium enemas, $\mathrm{X}$-ray examination of the lungs and skeleton, cystoscopies, and sigmoidoscopies. All patients underwent computed tomography (CT) (57.8\%) or magnetic resonance imaging (MRI) (63.3\%) scans to evaluate pelvic or para-aortic lymph node involvement. Positron emission tomography (PET) or PET-CT scans were performed in 21 patients (23.3\%). In the image interpretation of CT or MRI, the principal criterion for metastatic node involvement was the axial diameter of the lymph node. The presence of lymph nodes larger than $1 \mathrm{~cm}$ in the shortaxis dimension was considered to indicate metastatic node involvement. Additionally, we regarded central necrosis as a significant criterion for metastatic disease within the lymph node [12]. In the image interpretation of PET or PET-CT, a malignant lymphadenopathy was defined as follows: 1) fluorodeoxyglucose (FDG) accumulation greater than liver accumulation or similar to brain cortex accumulation, or 2) standardized uptake value of a lesion that corresponded to $\mathrm{CT}$ and did not decrease on the delayed PET image compared with the initial PET image [13]. Para-aortic lymph nodes were surgically assessed in 7 patients (7.8\%). Histologic classification was based on the World Health Organization classifications (Geneva, Switzerland).

\section{Radiotherapy}

All patients received a combination of external EFRT and high-dose-rate intracavitary brachytherapy (HDR-ICR). We used the box technique with parallel opposing fields for 87 patients or the two-field technique with antero-posterior fields for 3 patients. For para-aortic irradiation, we defined the T11-T12 or T12-L1 interspace covering the entire PAN as the superior border, $2 \mathrm{~cm}$ from the front of the vertebral body or enlarged lymph nodes as the anterior border, and the midline of the vertebral body as the posterior border, respectively. For whole pelvic irradiation, we defined the inferior border of the obturator foramen (if distal vaginal was not involved) or $2 \mathrm{~cm}$ below the lowest extent of the primary tumor (if there was distal vaginal invasion) as the inferior border, and $1.5 \mathrm{~cm}$ to $2 \mathrm{~cm}$ from the true bony pelvis as the lateral border in AP-PA fields. External EFRT was delivered using a 10-MV linear accelerator with a dose of 1.8-2 Gy per fraction, 5 times per week. Midline shielding with a $4 \mathrm{~cm}$-width was performed after the delivery of 26.0 to $45 \mathrm{~Gy}$ based on treatment response. This was followed by HDR-ICR using a remote afterloading system with a Ralstron 303 Co-60 source (Shimadzu, Kyoto, Japan) from 1979 to 1997, or a Gamma-Med II Ir-192 source (Sauerwein, Haan, Germany) from 1989 to 2006, or Multisource Ir-192 source (Eckert \& Ziegler BEBIG, Berlin, Germany) from 2007 onward. The total dose of HDR-ICR was 20-48 Gy, with 3 or 5 Gy per fraction, which was prescribed to point A. Overall, a 3 Gy per fraction with a median fraction number of 10 (range, 8-16) was prescribed for 43 patients and a 5 Gy per fraction with a median fraction number of 6 (range, 4-8) was administered to the others. After the completion of HDR-ICR, patients were administered a second course of external EFRT with midline shielding to a total external beam dose of 45 to 54 Gy. For patients with persistent residual disease, which was identified on pelvic examination and imaging studies performed at 1 month after planned EFRT and HDR-ICR, boost irradiation to the parametrium, pelvic wall, and involved node was performed. The median dose of boost irradiation was 9 Gy (range, 5.4-16 Gy).

\section{Chemotherapy}

Platinum single-agent or platinum-based doublet regimens were used. For concurrent chemoradiation (CCRT), protocols included two treatment schemes. One scheme was composed of three chemotherapy cycles administered at the beginning of the first, fourth, and seventh weeks of RT [14], and the regimen consisted of cisplatin $\left(70 \mathrm{mg} / \mathrm{m}^{2}\right)$ or carboplatin (area under the curve (AUC), 4) followed by five consecutive daily infusions of 5 -FU $\left(1000 \mathrm{mg} / \mathrm{m}^{2} /\right.$ day $)$. Weekly administration of cisplatin $\left(40 \mathrm{mg} / \mathrm{m}^{2}\right)$ or carboplatin (AUC, 2) during RT has been performed since the publication of randomized trials [15].

\section{Follow-up}

During treatment, adverse effects and performance levels were monitored weekly. After completion of treatment, 
Table 1 Patient characteristics

\begin{tabular}{|c|c|c|}
\hline \multirow[t]{2}{*}{ Characteristics } & \multicolumn{2}{|c|}{$\begin{array}{l}\text { Total patients } \\
(\mathrm{n}=90)\end{array}$} \\
\hline & $\mathrm{n}$ & (\%) \\
\hline \multicolumn{3}{|l|}{ Age } \\
\hline Median & 50 & \\
\hline Range & $(24-77)$ & \\
\hline \multicolumn{3}{|l|}{ ECOG performance } \\
\hline 0 & 55 & 61.1 \\
\hline 1 & 33 & 36.7 \\
\hline 2 & 2 & 2.2 \\
\hline \multicolumn{3}{|l|}{ Pathologic findings } \\
\hline Squamous cell carcinoma (SCC) & 84 & 93.3 \\
\hline Large cell keratinizing & 18 & 20 \\
\hline Large cell non-keratinizing & 47 & 52.2 \\
\hline Large cell, not specified & 3 & 3.3 \\
\hline SCC, not specified & 14 & 15.6 \\
\hline Small cell & 2 & 2.2 \\
\hline $\begin{array}{l}\text { Others (adenocarcinoma, } \\
\text { adenosquamous carcinoma) }\end{array}$ & 6 & 6.7 \\
\hline \multicolumn{3}{|l|}{ Tumor shape } \\
\hline Exophytic & 38 & 42.2 \\
\hline Infiltrative & 52 & 57.8 \\
\hline \multicolumn{3}{|l|}{ Parametrial involvement } \\
\hline No & 10 & 11.1 \\
\hline Yes & 80 & 88.9 \\
\hline Unilateral & 42 & 46.7 \\
\hline Bilateral & 38 & 42.2 \\
\hline \multicolumn{3}{|l|}{ Endocervical extension } \\
\hline No & 6 & 6.7 \\
\hline Yes & 37 & 41.1 \\
\hline Not confirmed & 47 & 52.2 \\
\hline \multicolumn{3}{|l|}{ Primary tumor size $(\mathrm{cm})$} \\
\hline Median & 5 & \\
\hline Range & $(2-10)$ & \\
\hline Pelvic LN involvement & 73 & 81.1 \\
\hline Paraaortic LN involvement & 90 & 100 \\
\hline Hydronephrosis & 18 & 20 \\
\hline \multicolumn{3}{|l|}{ FIGO stage } \\
\hline IB & 10 & 11.1 \\
\hline$\| \mathrm{B}$ & 39 & 43.3 \\
\hline$\| I I A$ & 2 & 2.2 \\
\hline$\| I \mathrm{~B}$ & 33 & 36.7 \\
\hline IVA & 6 & 6.7 \\
\hline
\end{tabular}

Table 1 Patient characteristics (Continued)

\begin{tabular}{lll}
\hline Treatment period & & \\
Before 2000 & 52 & 57.8 \\
2000-present & 38 & 42.2 \\
\hline Abbreviation: ECOG Eastern Cooperative Oncology Group performance.
\end{tabular}

all patients were evaluated at 1 month and every 3 months for the first 2 years, and every 6 months thereafter. Acute treatment-related hematologic toxicities were defined according to the National Cancer Institute Common Terminology Criteria for Adverse Events, version 4.0. Acute toxicities were evaluated from the start of treatment to 3 months following the completion of treatment. Depending on the severity and duration of toxicity, treatment was interrupted until the patient recovered. Late treatmentrelated toxicities were assessed using the Late Radiation Morbidity Scoring Scheme of the Radiation Therapy Oncology Group and the European Organization for Research and Treatment of Cancer. Late radiation toxicities developing later than 6 months after the completion of treatment were grouped into rectal, bladder, small bowel, and other complications.

We defined a complete remission (CR) as 100\% decrease of gross tumor on clinical evaluation or radiologic images. Partial response (PR) and progressive disease (PD) were defined as $\geq 50 \%$ decrease and $>25 \%$ increase of primary gross tumor, respectively. Anything else was categorized as stable disease. We evaluated treatment responses by performing history taking, physical and pelvic examinations, and imaging studies, such as MRI or CT scan, at 3 months after completion of all treatments. The follow-up imaging studies were performed routinely at $1,3,6,12,18$, and 24 months after treatment completion, and once a year thereafter. We defined local recurrence as any relapse or persistent disease at the cervix, vagina, parametrium, or pelvic wall. Regional recurrence was defined as node relapse within the RT field. Although PAN relapse is considered as a distant metastasis in the TNM staging system, PAN relapse was classified as a regional recurrence in this study. We defined distant metastasis as relapse outside the RT field.

\section{Statistical analysis}

Total dose to point A (Gy) was calculated by combining the dose of external beam irradiation before midline shielding and the total dose to point A in HDR-ICR. Overall actuarial survival (OS) and progression-free survival (PFS) were calculated using the Kaplan-Meier method and differences in survival rates were compared by the log-rank test. The OS time was calculated from the date of RT start to the date of death or last followup. The PFS time was calculated from the date of RT start to the date of disease progression, relapse, initiation of new unplanned anticancer therapy, disease-related 
death, or last follow-up. We analyzed prognostic factors for OS and PFS using a Cox regression method. Significant variables on univariate analysis were utilized for multivariate analysis to establish independent prognostic factors for OS and PFS. Differences in nominal variables were compared using Pearson's $\chi^{2}$ test or Fisher's exact test. We analyzed difference in continuous variables using the Mann-Whitney $U$ test. We considered statistical significance as $\mathrm{p}$ value $\leq 0.05$.

\section{Results}

\section{Patient and treatment characteristics}

All patient and treatment characteristics are listed in Tables 1 and 2, respectively. Patients received a median of 70.2 Gy to point A and a median of 50.4 Gy to PAN over a median of 69 elapsed days. Forty-six patients (51.1\%) received concurrent chemotherapy.

\section{Treatment-related toxicities}

Fourteen patients $(15.6 \%)$ exhibited grade 3 or 4 acute leukopenia, 12 (13.3\%) exhibited grade 3 or 4 acute anemia, and $12(13.3 \%)$ exhibited grade 3 or 4 acute thrombocytopenia. Grade 3 late gastrointestinal and urogenital toxicities were observed in $8(8.9 \%)$ and 3 patients (3.3\%), respectively. There was no grade 5 acute or late treatmentrelated toxicity.

\section{Treatment responses, patterns of failure, and survival analyses}

Seventy patients (77.8\%) had CR and 20 patients (22.2\%) had PR. No SD or persistent disease was observed in any patient. For PAN metastasis only, CR was observed in 75 patients $(83.3 \%)$ and PR in 15 patients (16.7\%). Forty-six patients experienced treatment failure (Table 3 ).

The median follow-up period for surviving patients was 55 months (range, 3-252). The 5-year OS and PFS for all patients were $62.6 \%$ and $43.9 \%$, respectively. In univariate analysis, ECOG PS (0 vs. 1 or 2, 5 -yr OS $72.3 \%$ vs. $44.5 \%$, $\mathrm{p}=0.04$ ) and treatment response (CR vs. PR, 5-yr OS $68.8 \%$ vs. $35.8 \%, p=0.01$ ) showed a significant effect on OS. Using multivariate analysis, treatment response was the only statistically significant factor for OS ( $\mathrm{p}=0.04$, hazard ratio (HR) 0.43, 95\% confidence interval (95\% CI) 0.19-0.98, Table 4 and Figure 1a). PFS was significantly associated with ECOG PS (0 vs. 1 or 2, 5-yr PFS $54.4 \%$ vs. $23.9 \%$, $\mathrm{p}=0.02$ ) and treatment response (CR vs. PR, 5-yr PFS $55.0 \%$ vs. $0 \%, \mathrm{p}<0.001)$ in the univariate analysis, and tumor shape showed significant trends for worse PFS. In the multivariate analysis, only treatment response had a significant influence on PFS ( $\mathrm{p}<0.001, \mathrm{HR} 0.3,95 \% \mathrm{CI}$ 0.16-0.58, Table 4 and Figure $1 \mathrm{~b}$ ). Treatment response (CR vs. PR) in PAN metastasis only was also associated significantly with OS (HR 0.25, 95\% CI 0.11-0.58, p = 0.001) and PFS (HR 0.27, 95\% CI 0.14-0.54, p < 0.001).
Table 2 Treatment characteristics

\begin{tabular}{llc}
\hline Characteristics & $\mathbf{n}$ & (\%) \\
\hline Radiotherapy field & & \\
Whole pelvis and lower para-aortic lymphatics & 4 & 4.4 \\
Whole pelvis and entire para-aortic lymphatics & 86 & 95.6 \\
Chemotherapy & & \\
None & 44 & 48.9 \\
Concurrent chemotherapy & 46 & 51.1 \\
$\quad$ Weekly cisplatin or carboplatin & 24 & 26.6 \\
$\quad$ Cisplatin or carboplatin followed by 5-FU & 22 & \\
Total dose to point A (Gy) & & \\
Median & 70.2 & \\
Range & $(56-93)$ & \\
Interquartile range (75th and 25th percentiles) & $14.4(80.4,66)$ & \\
Total dose to para-aortic lymphatics & & \\
Median & 50.4 & \\
Range & $(45-60.4)$ & \\
Interquartile range (75th and 25th percentiles) & $3.6(54,50.4)$ & \\
Radiotherapy duration (days) & & \\
Median & 69 & $(43-182)$ \\
Range & $20(80,60)$ & \\
Interquartile range (75th and 25th percentiles) & & \\
\hline
\end{tabular}

Table 3 Patterns of failure

\begin{tabular}{lll}
\hline Patterns of failure & $\mathbf{n}$ & $\mathbf{( \% )}$ \\
\hline Local recurrence & 11 & 12.2 \\
Cervix & 7 & 7.8 \\
Vagina & 3 & 3.3 \\
Parametrium/pelvic wall & 2 & 2.2 \\
Regional recurrence & 19 & 21 \\
Pelvic lymph node & 10 & 11.1 \\
Paraaortic lymph node & 13 & 14.4 \\
Distant metastasis & 33 & 36.7 \\
Outfield nodal failure & 21 & 23.3 \\
Bone & 4 & 4.4 \\
Viscera & 12 & 13.3 \\
Liver & 4 & 4.4 \\
Lung & 7 & 7.8 \\
Spleen & 1 & 1.1 \\
Ureter & 1 & 1.1 \\
Carcinomatosis & 5 & 5.6 \\
\hline
\end{tabular}


Table 4 Prognostic factors on overall survival and progression-free survival by Cox proportional-hazards model

\begin{tabular}{|c|c|c|c|c|c|c|c|c|}
\hline \multirow[b]{3}{*}{ Variables } & \multicolumn{4}{|l|}{ Overall survival } & \multicolumn{4}{|c|}{ Progression-free survival } \\
\hline & \multicolumn{2}{|l|}{ Univariate analysis } & \multicolumn{2}{|c|}{ Multivariate analysis } & \multicolumn{2}{|l|}{ Univariate analysis } & \multicolumn{2}{|c|}{ Multivariate analysis } \\
\hline & HR (95\% Cl) & $p$ value & $\mathrm{HR}(95 \% \mathrm{Cl})$ & $p$ value & HR (95\% Cl) & $p$ value & HR (95\% Cl) & $p$ value \\
\hline Age (<50 vs. $\geq 50)$ & $1.21(0.59-2.51)$ & 0.61 & & & $1.24(0.69-2.21)$ & 0.47 & & \\
\hline ECOG PS (0 vs. 1 or 2 ) & $0.45(0.22-0.95)$ & 0.04 & $0.53(0.25-1.12)$ & 0.1 & $0.48(0.27-0.87)$ & 0.02 & $0.57(0.31-1.03)$ & 0.06 \\
\hline Tumor shape (exophytic vs. infiltrative) & $1.75(0.85-3.64)$ & 0.13 & & & $1.75(0.98-3.14)$ & 0.06 & $1.67(0.93-2.99)$ & 0.09 \\
\hline Tumor size ( $<5$ vs. $\geq 5 \mathrm{~cm})$ & $0.67(0.3-1.47)$ & 0.31 & & & $0.72(0.39-1.33)$ & 0.29 & & \\
\hline Parametrial involvement (no vs. yes) & $0.4(0.1-1.7)$ & 0.22 & & & $0.5(0.18-1.39)$ & 0.18 & & \\
\hline Endocervical extension (others vs. yes) & $1.85(0.82-4.17)$ & 0.14 & & & $1.47(0.8-2.7)$ & 0.22 & & \\
\hline Pelvic nodal involvement (no vs. yes) & $0.78(0.32-1.91)$ & 0.58 & & & $0.71(0.34-1.47)$ & 0.35 & & \\
\hline Hydronephrosis (no vs. yes) & $1.21(0.42-3.5)$ & 0.72 & & & $0.82(0.4-1.65)$ & 0.57 & & \\
\hline \multirow[t]{2}{*}{ Stage (IB vs. IIB vs. IIIA-IVA) } & Referent $0.38(0.09-1.7)$ & 0.45 & & & Referent $0.45(0.15-1.3)$ & 0.32 & & \\
\hline & $0.9(0.42-1.92)$ & & & & $0.81(0.44-1.49)$ & & & \\
\hline Radiotherapy duration ( $<10$ vs. $\geq 10$ weeks) & $0.59(0.28-1.23)$ & 0.16 & & & $0.62(0.35-1.12)$ & 0.11 & & \\
\hline Doses to point A (<75 vs. $\geq 75$ Gy) & $0.87(0.42-1.8)$ & 0.71 & & & $0.64(0.36-1.15)$ & 0.14 & & \\
\hline Doses to PAN (<50.4 vs. $\geq 50.4$ Gy) & $1.09(0.46-2.55)$ & 0.85 & & & $0.75(0.35-1.6)$ & 0.45 & & \\
\hline Treatment period (<2000 vs. $\geq 2000$ ) & $1.25(0.59-2.65)$ & 0.56 & & & $0.98(0.54-1.76)$ & 0.95 & & \\
\hline Treatment response (CR vs. PR) & $0.36(0.16-0.81)$ & 0.01 & $0.43(0.19-0.98)$ & 0.04 & $0.27(0.14-0.51)$ & $<0.001$ & $0.3(0.16-0.58)$ & $<0.001$ \\
\hline Concurrent chemotherapy (no vs. yes) & $1.23(0.59-2.54)$ & 0.59 & & & $0.88(0.49-1.57)$ & 0.65 & & \\
\hline
\end{tabular}

Abbreviation: ECOG PS Eastern Cooperative Oncology Group performance status, $C R$ complete remission, $P R$ partial response, $H R$ hazard ratio, $C l$ confidence interval. 
a)

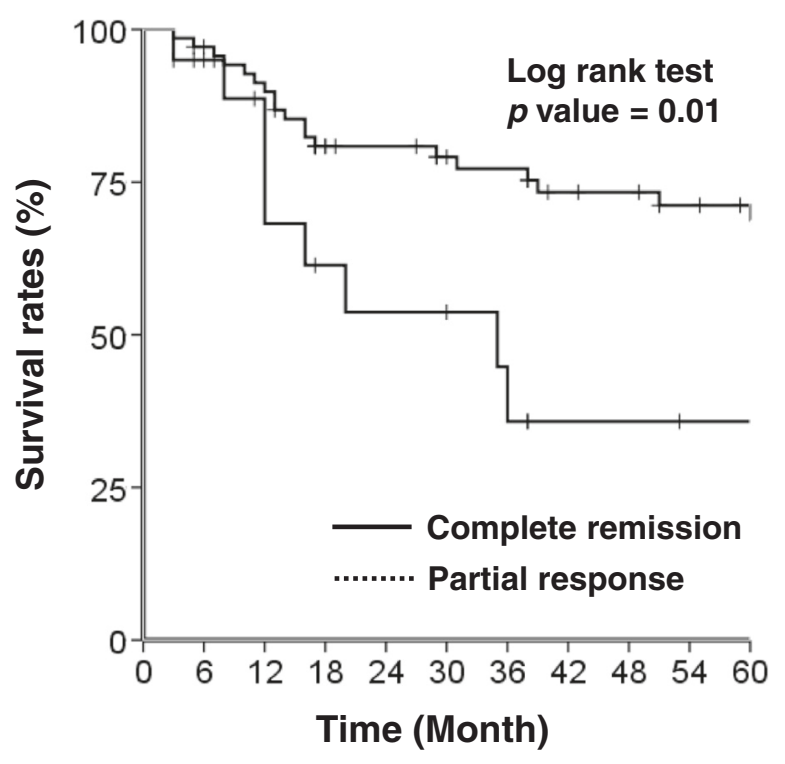

No. at Risk

$\begin{array}{rlllllllllll}\text { Complete remission } & 70 & 67 & 60 & 49 & 46 & 43 & 40 & 36 & 34 & 31 & 16 \\ \text { Partial response } & 20 & 16 & 13 & 8 & 7 & 7 & 4 & 2 & 2 & 1 & 1\end{array}$

b)

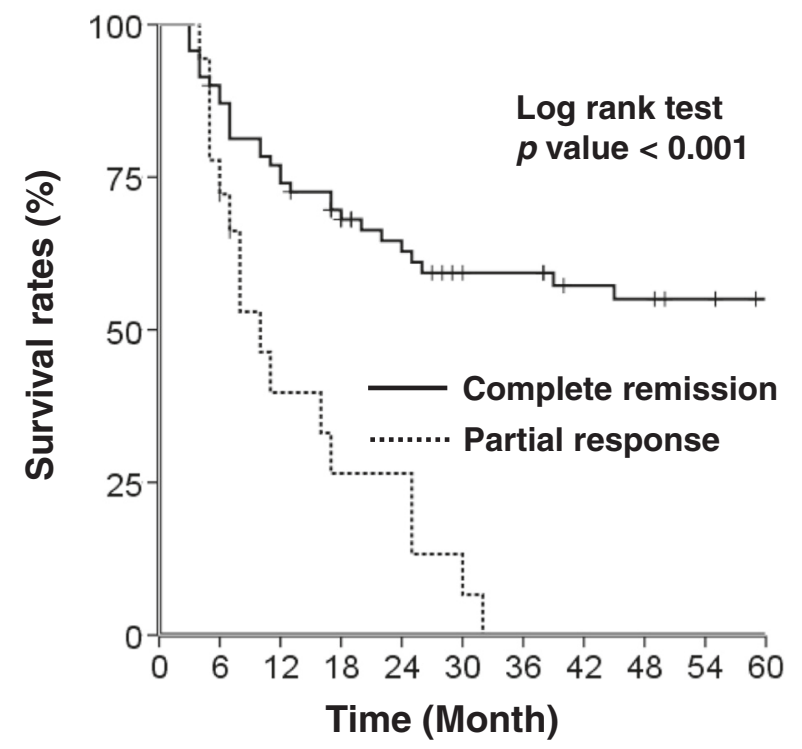

No. at Risk

$\begin{array}{rlllllllllll}\text { Complete remission } & 70 & 62 & 52 & 43 & 36 & 31 & 29 & 26 & 24 & 22 & 11 \\ \text { Partial response } & 20 & 13 & 6 & 4 & 4 & 2 & 0 & 0 & 0 & 0 & 0\end{array}$

Figure 1 Kaplan-Meier curves of (a) 5-year overall survival rate (log rank test $p=0.01$ ) and (b) progression-free survival rate (log rank test $p<0.001$ ) according to the treatment response.

Does the concurrent chemotherapy provide survival benefits?

The addition of concurrent chemotherapy was not related to OS or PFS in our univariate analysis (Table 4 and Figure 2). Comparing toxicities, we observed severe acute hematologic toxicity (grade 3 to 4 ) significantly more often in patients receiving EFRT plus concurrent chemotherapy then in those receiving EFRT alone (Table 5). Although severe acute toxicity upon the addition of chemotherapy did not generate a statistical 
a)

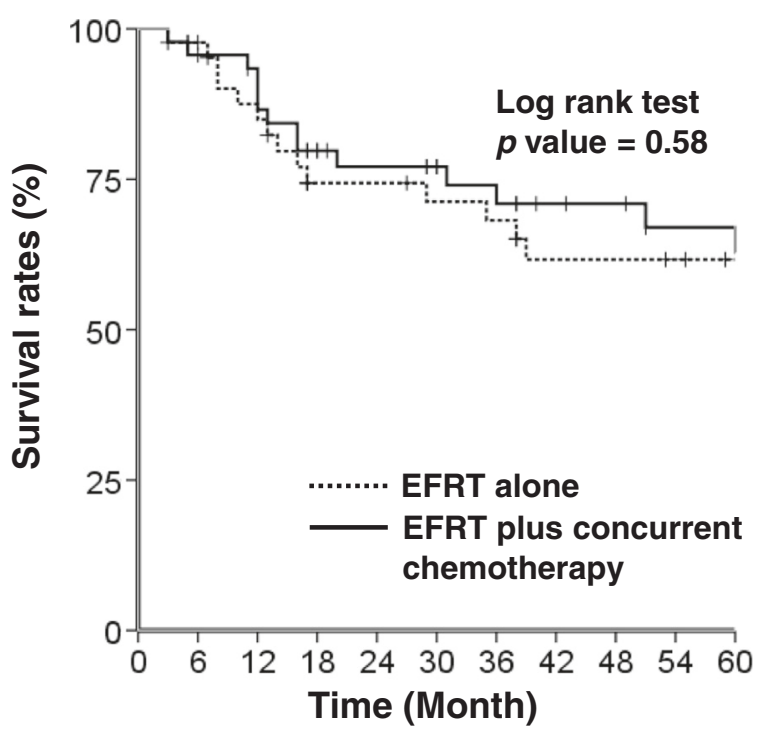

No. at Risk

$\begin{array}{llllllllllll}\text { EFRT alone } & 44 & 39 & 32 & 25 & 25 & 23 & 21 & 18 & 18 & 16 & 8\end{array}$

EFRT plus concurrent chemotherapy
$\begin{array}{lll}44 & 39 \\ 46 & 33 & 40\end{array}$
$\begin{array}{lllllllllll}46 & 43 & 40 & 32 & 28 & 26 & 23 & 20 & 18 & 16 & 9\end{array}$

b)

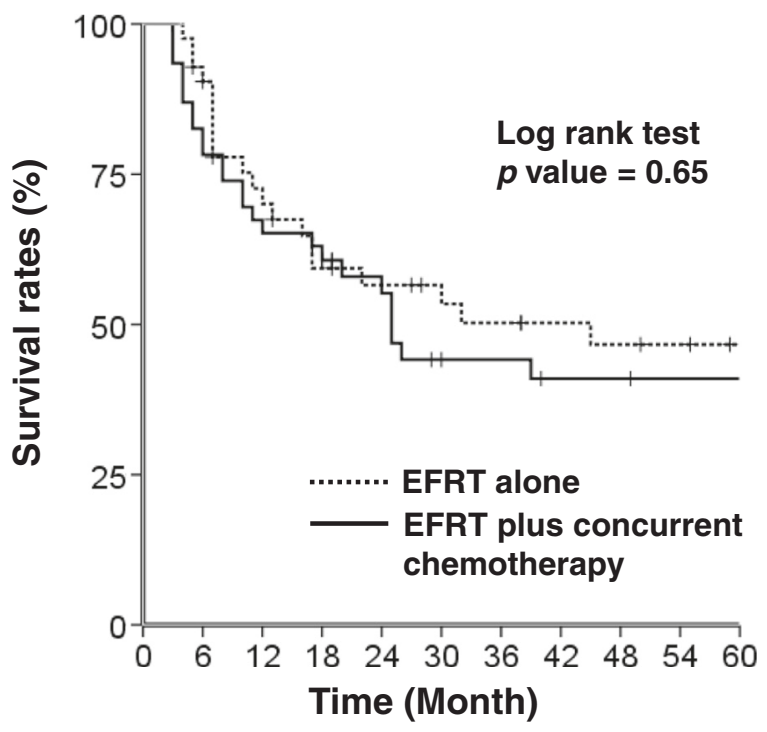

No. at Risk

EFRT alone

EFRT plus concurrent chemotherapy
$\begin{array}{lll}44 & 37 \quad 28\end{array}$
2219
$18 \quad 15$
$13 \quad 11 \quad 6$
$\begin{array}{lllllllllll}46 & 38 & 30 & 25 & 21 & 15 & 14 & 12 & 12 & 11 & 6\end{array}$

Figure 2 Kaplan-Meier curves of (a) 5-year overall survival rate (log rank test $p=0.58$ ) and (b) progression-free survival rate (log rank test $p=0.65$ ) according to the addition of concurrent chemotherapy to EFRT.

difference in treatment duration $(\mathrm{p}=0.18$, median 67 vs. 71 days), patients showing severe acute hematologic toxicity in the EFRT plus chemotherapy group showed longer treatment durations (median 81 days, 43-182) than the others (median 64 days, 47-129, $\mathrm{p}<0.001$ ). Radiationinduced proctitis, cystitis, enteritis, and vesicovaginal fistula were observed as severe late toxicities. The interval between the start of treatment and the appearance of toxicities was a median of 15 months; the interval in the EFRT plus chemotherapy group was shorter than that for the EFRT alone group (median 13 vs. 27 months, respectively). There was no significant difference in treatment 


\begin{tabular}{|c|c|c|c|}
\hline \multirow[b]{2}{*}{ Toxicity } & \multicolumn{2}{|c|}{ Grade 3-4 } & \multirow[t]{2}{*}{$p$ value } \\
\hline & $\begin{array}{l}\text { None } \\
(n=44)\end{array}$ & $\begin{array}{l}\text { Concurrent CTx } \\
(n=46)\end{array}$ & \\
\hline \multicolumn{4}{|l|}{ Acute } \\
\hline Leukopenia & $0(0.0)$ & $14(30.4)$ & $<0.001$ \\
\hline Anemia & $0(0.0)$ & $12(26.1)$ & $<0.001$ \\
\hline Thrombocytopenia & $0(0.0)$ & $12(26.1)$ & $<0.001$ \\
\hline \multicolumn{4}{|l|}{ Late } \\
\hline Rectal & $4(9.1)$ & $4(8.7)$ & 1 \\
\hline Bladder & $3(6.8)$ & $0(0.0)$ & 0.11 \\
\hline Small bowel & $0(0.0)$ & $1(2.2)$ & 1 \\
\hline Vagina vault necrosis & $0(0.0)$ & $0(0.0)$ & - \\
\hline
\end{tabular}

Abbreviation: CTx concurrent chemotherapy.

response (CR and PR rates, $75 \%$ and $25 \%$ in EFRT alone vs. $80.4 \%$ and $19.6 \%$ in EFRT plus concurrent chemotherapy, $\mathrm{p}=0.42$ ) or patterns of failure according to addition of chemotherapy (Additional file 1: Table S1).

\section{Discussion}

This study showed that EFRT was an efficient treatment for uterine cervical cancer with involved PAN, with a 5year OS of $62.6 \%$ and PFS of $43.9 \%$. Treatment response was an independent prognostic factor for survival. The addition of concurrent chemotherapy to EFRT did not affect treatment response, patterns of failure, OS, or PFS, but rather, was associated with severe treatmentrelated toxicity.

Although patients who underwent EFRT alone were irradiated with a median of 54 Gy without a radiosensitizing chemotherapeutic agent, treatment response rates were not different from patients receiving a median of 50.4 Gy in EFRT plus concurrent chemotherapy. A previous study demonstrated that concurrent chemotherapy did not affect overall survival in isolated PAN recurred cervical cancer patients receiving a median of 50.8 Gy of RT to PAN ( $\mathrm{p}=0.69$ ) [16]. Therein, a total dose of $\geq 51$ Gy tended to show higher survival than that of $<51$ Gy $(p=0.07)$. Based on that previous study, we also considered that 54 Gy of EFRT alone would be sufficient to control PAN metastasis without radiosensitizing chemotherapy. Nevertheless, further study is necessary.

For patients initially diagnosed with PAN metastasis, the efficacy of concurrent chemotherapy seems to be uncertain. Since Stryker et al. reported that cisplatin-based chemotherapy may be beneficial [3], many studies have continued to report favorable outcomes, despite more acute severe hematologic and gastrointestinal toxicity $[7-9,17,18]$. In reviewing our results, we did not observe a significant survival benefit for the addition of concurrent chemotherapy to EFRT, although the group that received EFRT alone included more patients with disease of advanced stage ( $<<0.001$, Additional file 1: Table S2). This implies that survival benefit of EFRT plus concurrent chemotherapy is insignificant for uterine cervical cancer with PAN metastasis, suggesting that more effective chemotherapeutic regimen and scheme would be required.

However, along with no difference in PFS according to the addition of chemotherapy, the OS rates between EFRT alone and EFRT plus concurrent chemotherapy also showed no statistically significant difference. Due to the different periods of treatment according to the addition of chemotherapy (Additional file 1: Table S2), we questioned whether differences in therapeutic standards, such as salvage treatment, induced by the treatment year could affect survival. Advances in RT [19-21] and chemotherapy $[22,23]$ over the years have increased the success rates of salvage treatments $[24,25]$. In this study, patients treated with EFRT plus concurrent chemotherapy received more salvage treatments $(80.0 \%$ vs. $52.4 \%, \mathrm{p}=0.047)$, especially salvage chemotherapy ( $64 \%$ vs. $23.8 \%, \mathrm{p}=0.006)$, after relapse (Additional file 1: Table S3). In the survival analysis of relapsed patients only, patients receiving salvage treatment showed significantly improved OS, compared to those receiving only conservative care (median OS 51 vs. 13 months, $\mathrm{p}<0.001$, Additional file 2: Figure S1). Therefore, it is possible that different treatment years may result in survival differences according to the addition of chemotherapy in this study. The effect of additional chemotherapy to EFRT in uterine cervical cancer with metastatic PAN warrants investigation via a randomized clinical trial. However, since enrolling participants in an EFRT alone group in a prospective trial would be difficult, we are limited to indirect investigations through retrospective trials.

Special considerations are needed to understand our findings because of several drawbacks. Since this study is a retrospective review covering a long period (over 20 years), heterogeneity of patient characteristics might have confused diagnosis, treatment, follow-up, and our results, including treatment response and toxicity. Viewed in this light, the most important consideration is the accuracy of the PAN metastasis diagnosis. PAN metastasis was pathologically confirmed in a small number of patients of this study. Most cases depended on several imaging studies, including CT, MRI, PET, and PET-CT, due to the development of imaging tools over a long time [26-29]. However, as all patients underwent CT or MRI scans in this study, we expect that there would not be many differences in initial staging of lymph node involvement, despite a long treatment period. As well, the long period could have affected whether or not concurrent chemotherapy was undertaken: the benefits of cisplatin-based concurrent chemoradiotherapy were reported in 1999 [30]. Accordingly, 
after 2000, the EFRT alone group in this study comprised only $9.1 \%$ of patients, and most patients were treated with EFRT plus concurrent chemotherapy. Accordingly, we evaluated treatment period as a prognostic factor in the univariate and multivariate analyses of survival rates. However, treatment period did not affect OS and PFS significantly. Chemotherapeutic regimens and schemes were also heterogeneous, which might have influenced treatment outcomes. On prognostic factors analysis using a Cox regression method confined to patients receiving concurrent chemotherapy, difference in chemotherapy scheme was not a significant prognostic factor for OS and PFS (data not shown). Since all patients who underwent EFRT plus concurrent chemotherapy in this study received platinumbased regimens $[30,31]$ and since the addition of chemotherapy and difference in chemotherapy scheme did not affect survival, we do not consider the heterogeneity of chemotherapeutic regimens and schemes to have affected OS and PFS.

In conclusion, we suggest that EFRT with or without concurrent chemotherapy can be an effective treatment for cervical cancer patients with para-aortic node metastasis. Treatment response was a significant prognostic factor for OS and PFS, respectively. Our findings showed the controversial effects of the addition of concurrent chemotherapy to EFRT. Although they should be interpreted cautiously, due to the heterogeneity in this study, our findings deserve consideration, since performing a randomized clinical trial would be impractical.

\section{Additional files}

Additional file 1: Table S1. Patterns of failure according to the addition of chemotherapy. Table S2. Patient and treatment characteristics according to the addition of chemotherapy. Table S3. Salvage treatments after first recurrence according to treatment modality in relapsed patients.

Additional file 2: Figure S1. Kaplan-Meier curve depicts that patients receiving salvage treatment showed significantly improved overall survival rates compared to those receiving only conservative care after relapse (median OS 51 vs. 13 months, $p<0.001$ ).

\section{Competing interests}

The authors declare that they have no competing interests.

\section{Authors' contributions}

All authors read and approved the final manuscript.

\section{Acknowledgements}

This study was supported by a faculty research grant of Yonsei University College of Medicine for 2012 (6-2012-0187).

\section{Author details}

'Department of Radiation Oncology, Yonsei Cancer Center, Yonsei University College of Medicine, 50-1 Yonsei-ro, Seodaemun-gu, Seoul 120-752, Korea. ${ }^{2}$ Department of Radiation Oncology, Yonsei University Wonju College of Medicine, Wonju, Korea. ${ }^{3}$ Division of Gynecologic Oncology, Department of Obstetrics and Gynecology, Yonsei University College of Medicine, Seoul, Korea. ${ }^{4}$ Department of Radiation Oncology, Jeju National University School of Medicine, Jeju, Korea. ${ }^{5}$ Department of Pharmacology, Brain Korea 21 plus
Project for Medical Science, Yonsei University College of Medicine, Seoul, Korea. ${ }^{6}$ Yonsei Song-Dang Institute for Cancer Research, Yonsei University College of Medicine, Seoul, Korea.

Received: 21 July 2014 Accepted: 23 December 2014

Published online: 13 January 2015

\section{References}

1. Stehman FB, Bundy BN, DiSaia PJ, Keys HM, Larson JE, Fowler WC. Carcinoma of the cervix treated with radiation therapy. I. A multi-variate analysis of prognostic variables in the Gynecologic Oncology Group. Cancer. 1991;67:2776-85

2. Berman ML, Keys H, Creasman W, DiSaia P, Bundy B, Blessing J. Survival and patterns of recurrence in cervical cancer metastatic to periaortic lymph nodes (a Gynecologic Oncology Group study). Gynecol Oncol. 1984;19:8-16.

3. Stryker JA, Mortel R. Survival following extended field irradiation in carcinoma of cervix metastatic to para-aortic lymph nodes. Gynecol Oncol. 2000;79:399-405

4. Grigsby PW, Perez CA, Chao KS, Herzog T, Mutch DG, Rader J. Radiation therapy for carcinoma of the cervix with biopsy-proven positive para-aortic lymph nodes. Int J Radiat Oncol Biol Phys. 2001;49:733-8.

5. Podczaski E, Stryker JA, Kaminski P, Ndubisi B, Larson J, DeGeest K, et al. Extended-field radiation therapy for carcinoma of the cervix. Cancer. 1990;66:251-8.

6. Small Jr W, Winter K, Levenback C, lyer R, Gaffney D, Asbell S, et al. Extended-field irradiation and intracavitary brachytherapy combined with cisplatin chemotherapy for cervical cancer with positive para-aortic or high common iliac lymph nodes: results of ARM 1 of RTOG 0116. Int J Radiat Oncol Biol Phys. 2007;68:1081-7.

7. Kim YS, Kim JH, Ahn SD, Lee SW, Shin SS, Nam JH, et al. High-dose extended-field irradiation and high-dose-rate brachytherapy with concurrent chemotherapy for cervical cancer with positive para-aortic lymph nodes. Int J Radiat Oncol Biol Phys. 2009;74:1522-8.

8. Walker JL, Morrison A, DiSilvestro P, von Gruenigen VE. A phase I/II study of extended field radiation therapy with concomitant paclitaxel and cisplatin chemotherapy in patients with cervical carcinoma metastatic to the para-aortic lymph nodes: a Gynecologic Oncology Group study. Gynecol Oncol. 2009;112:78-84

9. Kazumoto $\mathrm{T}$, Kato $\mathrm{S}$, Yokota $\mathrm{H}$, Hasumi $\mathrm{Y}$, Kino $\mathrm{N}$, Horie $\mathrm{K}$, et al. Is a low dose of concomitant chemotherapy with extended-field radiotherapy acceptable as an efficient treatment for cervical cancer patients with metastases to the para-aortic lymph nodes? Int J Gynecol Cancer. 2011;21:1465-71.

10. Zhang G, Fu C, Zhang Y, Wang J, Qiao N, Yang Q, et al. Extended-field intensity-modulated radiotherapy and concurrent cisplatin-based chemotherapy for postoperative cervical cancer with common iliac or para-aortic lymph node metastases: a retrospective review in a single institution. Int J Gynecol Cancer. 2012;22:1220-5.

11. Pecorelli S. Revised FIGO staging for carcinoma of the vulva, cervix, and endometrium. Int J Gynaecol Obstet. 2009;105:103-4.

12. Follen M, Levenback CF, lyer RB, Grigsby PW, Boss EA, Delpassand ES, et al. Imaging in cervical cancer. Cancer. 2003;98:2028-38.

13. Choi HJ, Roh JW, Seo SS, Lee S, Kim JY, Kim SK, et al. Comparison of the accuracy of magnetic resonance imaging and positron emission tomography/computed tomography in the presurgical detection of lymph node metastases in patients with uterine cervical carcinoma: a prospective study. Cancer. 2006;106:914-22.

14. Kim YB, Cho JH, Keum KC, Lee CG, Seong J, Suh CO, et al. Concurrent chemoradiotherapy followed by adjuvant chemotherapy in uterine cervical cancer patients with high-risk factors. Gynecol Oncol. 2007;104:58-63.

15. Pearcey R, Brundage M, Drouin P, Jeffrey J, Johnston D, Lukka H, et al. Phase III trial comparing radical radiotherapy with and without cisplatin chemotherapy in patients with advanced squamous cell cancer of the cervix. J Clin Oncol. 2002;20:966-72.

16. Niibe Y, Kenjo M, Kazumoto T, Michimoto K, Takayama M, Yamauchi C, et al. Multi-institutional study of radiation therapy for isolated para-aortic lymph node recurrence in uterine cervical carcinoma: 84 subjects of a population of more than 5,000. Int J Radiat Oncol Biol Phys. 2006;66:1366-9.

17. Kim JY, Kim JY, Kim JH, Yoon MS, Kim J, Kim YS. Curative chemoradiotherapy in patients with stage IVB cervical cancer presenting with paraortic and left supraclavicular lymph node metastases. Int J Radiat Oncol Biol Phys. 2012;84:741-7. 
18. Small Jr W, Winter K, Levenback C, lyer R, Hymes SR, Jhingran A, et al. Extended-field irradiation and intracavitary brachytherapy combined with cisplatin and amifostine for cervical cancer with positive para-aortic or high common iliac lymph nodes: results of arm II of Radiation Therapy Oncology Group (RTOG) 0116. Int J Gynecol Cancer. 2011;21:1266-75.

19. Intensity Modulated Radiation Therapy Collaborative Working G. Intensitymodulated radiotherapy: current status and issues of interest. Int J Radiat Oncol Biol Phys. 2001;51:880-914.

20. Cattaneo GM, Dell'oca I, Broggi S, Fiorino C, Perna L, Pasetti M, et al. Treatment planning comparison between conformal radiotherapy and helical tomotherapy in the case of locally advanced-stage NSCLC. Radiother Oncol. 2008;88:310-8.

21. Jeong S, Yoo EJ, Kim JY, Han CW, Kim KJ, Kay CS. Re-irradiation of unresectable recurrent head and neck cancer: using Helical Tomotherapy as image-guided intensity-modulated radiotherapy. Radiat Oncol J. 2013;31:206-15.

22. Moore KN, Herzog TJ, Lewin S, Giuntoli RL, Armstrong DK, Rocconi RP, et al. A comparison of cisplatin/paclitaxel and carboplatin/paclitaxel in stage IVB recurrent or persistent cervical cancer. Gynecol Oncol. 2007;105:299-303.

23. Zagouri F, Sergentanis TN, Chrysikos D, Filipits M, Bartsch R. Molecularly targeted therapies in cervical cancer. A systematic review. Gynecol Oncol. 2012;126:291-303

24. Hong JH, Tsai CS, Lai CH, Chang TC, Wang CC, Chou HH, et al. Recurrent squamous cell carcinoma of cervix after definitive radiotherapy. Int J Radiat Oncol Biol Phys. 2004;60:249-57.

25. Monk BJ, Sill MW, McMeekin DS, Cohn DE, Ramondetta LM, Boardman CH, et al. Phase III trial of four cisplatin-containing doublet combinations in stage IVB, recurrent, or persistent cervical carcinoma: a Gynecologic Oncology Group study. J Clin Oncol. 2009:27:4649-55.

26. Whitley NO, Brenner DE, Francis A, Villa Santa U, Aisner J, Wiernik PH, et al. Computed tomographic evaluation of carcinoma of the cervix. Radiology. 1982;142:439-46.

27. Choi HJ, Kim SH, Seo SS, Kang S, Lee S, Kim JY, et al. MRI for pretreatment lymph node staging in uterine cervical cancer. AJR Am J Roentgenol. 2006;187:W538-43

28. Rose PG, Adler LP, Rodriguez M, Faulhaber PF, Abdul-Karim FW, Miraldi F. Positron emission tomography for evaluating para-aortic nodal metastasis in locally advanced cervical cancer before surgical staging: a surgicopathologic study. J Clin Oncol. 1999;17:41-5.

29. Kitajima K, Murakami K, Yamasaki E, Fukasawa I, Inaba N, Kaji Y, et al. Accuracy of 18F-FDG PET/CT in detecting pelvic and paraaortic lymph node metastasis in patients with endometrial cancer. AJR Am J Roentgenol. 2008;190:1652-8.

30. Rose PG, Bundy BN, Watkins EB, Thigpen JT, Deppe G, Maiman MA, et al Concurrent cisplatin-based radiotherapy and chemotherapy for locally advanced cervical cancer. N Engl J Med. 1999;340:1144-53.

31. Kim YS, Shin SS, Nam JH, Kim YT, Kim YM, Kim JH, et al. Prospective randomized comparison of monthly fluorouracil and cisplatin versus weekly cisplatin concurrent with pelvic radiotherapy and high-dose rate brachytherapy for locally advanced cervical cancer. Gynecol Oncol. 2008;108:195-200.

\section{Submit your next manuscript to BioMed Central and take full advantage of:}

- Convenient online submission

- Thorough peer review

- No space constraints or color figure charges

- Immediate publication on acceptance

- Inclusion in PubMed, CAS, Scopus and Google Scholar

- Research which is freely available for redistribution

Submit your manuscript at www.biomedcentral.com/submit 